\title{
Definição de atributos ambientais essenciais para a humanização em quartos de internação
}

\author{
Definition of essential environmental elements for the \\ humanization of hospital
}

\begin{abstract}
Juliana Tasca Tissot
Lizandra Gracia Lupi Vergara

Vera Helena Moro Bins Ely

E

$\mathrm{m}$ arquitetura, humanizar significa oferecer espaços mais qualificados aos usuários, com estímulos ambientais que propiciem bem-estar.

Estabelecimentos de saúde públicos raramente oferecem espaços para que os pacientes circulem, além do quarto de internação. Esta pesquisa busca investigar quais são os elementos ambientais essenciais para a humanização desses espaços através de revisão de literatura e um estudo de caso em hospital público. Assim, realizou-se uma revisão de literatura para elencar possíveis elementos capazes de gerar maior conforto e bem-estar físico e psicológico aos usuários, e aspectos relacionados à psicologia ambiental foram abordados para melhor compreensão do comportamento dos usuários. A pesquisa, de caráter investigativo, foi realizada por meio de um estudo de caso, com o apoio de diversos métodos quali/quantitativos, como: visita exploratória, inquirição, observação do comportamento e análise dos traços físicos - imprescindíveis para auxiliar na definição dos atributos prioritários. Os métodos foram aplicados com a finalidade de avaliar o ambiente, identificar os usuários e suas atividades. Pode-se concluir que os elementos ambientais considerados como essenciais são em sua maioria aqueles inerentes à própria arquitetura. Ao projetar ambientes de saúde, que possuem usuários fragilizados, devem-se levar em conta seus anseios e suas necessidades para garantir uma permanência satisfatória.
\end{abstract}

Palavras-chave: Humanização. Arquitetura hospitalar. Psicologia ambiental.
Abstract
In architecture, humanising means offering betterspaces to users, with environmental stimuli that enhance wellbeing. Public healthcare facilities rarely offer spaces for patients to move around in, in addition to the inpatient room. This studyseeks to investigate what arethe essential environmental elements for the humanisation of these spaces through a literature review and a case study in a public hospital. Thus, a literature review was carried out to list possible elements capable of generating greater comfort and physical and psychological wellbeing to users, where aspects related to environmental psychology were addressed to better understand users' behaviour. This investigative research was carried out through a case study, with the support of several quali / quantitative methods, such as: exploratory visit, inquiry, observation of behaviour and analysis of physical traits - essential to assist in the determination of the priorityatributes. The methods were applied in order to assess the environment and identify users and their activities. The studyconcludesthat the environmental elements considered essential are mostly those inherent to architecture itself. When designing healthcare environments, whoseusersarefrail, one must take into account their desires and needs in order to ensure a satisfactory stay.
Keywords: Humanisation. Healthcare design. Environmental psychology.

Recebido em 12/11/19

Aceito em 26/02/20

TISSOT, J. T.; VERGARA, L. G. L.; BINS ELY, V. H. M.Definição de atributos ambientais essenciais para a humanização 541 em quartos de internação. Ambiente Construído, Porto Alegre, v. 20, n. 3, p. 541-551, jul./set. 2020. ISSN 1678-8621 Associação Nacional de Tecnologia do Ambiente Construído. http://dx.doi.org/10.1590/s1678-86212020000300444 


\section{Introdução}

Desde o surgimento dos hospitais houve significativas mudanças em seu arranjo espacial, tanto devido à transformação na forma de atendimento à saúde, quanto na criação de leis e normas. Com o passar dos anos, novas tecnologias na arquitetura hospitalar e na forma de atendimento surgiram e contribuíram para que a saúde do paciente fosse tratada de forma mais cuidadosa, pois antigamente as pessoas buscavam os hospitais apenas como último recurso.

Percebe-se, no entanto, que dispor de bons profissionais e tecnologia de ponta deveria vir acompanhado de ambientes físicos adequados às reais necessidades dos usuários. A preocupação em afastá-los do caráter hostil e institucionalizado desses estabelecimentos ganha cada vez mais força, o que reforça a importância da humanização.

O tema humanização é bastante abrangente e além de considerar o bem-estar físico e psicológico dos usuários, leva em conta aspectos técnicos (atenção em saúde), sociais (visão ecológica e relacional das populações, estruturas organizacionais, entre outros) e as pessoas (sujeito como protagonista no processo). O HumanizaSUS é uma política de saúde que visa oferecer um serviço de atenção mais humanizado à população, a partir de ferramentas para consolidar redes, vínculos e a corresponsabilização entre usuários, trabalhadores e gestores. Humanizar é entendido como ofertar atendimento de qualidade ao articular os avanços tecnológicos com acolhimento, melhoria dos ambientes de cuidado e das condições de trabalho dos profissionais (BRASIL, 2010).

Por entender que um dos aspectos a ser considerado para a humanização é o ambiente físico e que o comportamento dos usuários possui uma relação direta com o espaço, torna-se importante, portanto, compreender os fenômenos da psicologia ambiental a fim de melhor interpretar os comportamentos das pessoas nos ambientes e poder assim projetar espaços mais responsivos. $\mathrm{O}$ foco principal é oferecer espaços mais qualificados e proporcionar aos usuários estímulos ambientais benéficos.

$\mathrm{Na}$ medida em que o estabelecimento de saúde começou a se tornar mais especializado, com diversos espaços para atender necessidades específicas - como diagnósticos, tratamentos, cirurgias, administração, refeição, entre outros - sua complexidade espacial cresceu em quantidade e qualidade (VERDERBER; FINE, 2000). A partir do século XXI, novas tipologias centradas na promoção da saúde começaram a ganhar forma e constituíram um modelo de assistência humanizado, focado na necessidade de autonomia e na qualidade de vida do paciente (ERIKSSON, 2001). Diante desse novo contexto, surgem requisitos para o planejamento de estabelecimentos de saúde que prestam suporte psicossocial aos seus usuários. Assim, há uma necessidade por estudos empíricos que verifiquem, investiguem e identifiquem fatores capazes de promover apoio psicológico e bem-estar ao usuário, pois está comprovado que o ambiente exerce influência sobre o comportamento humano (DILANI, 2001).

O usuário, ao perceber esses estímulos de forma positiva ou negativa, reage a eles com comportamentos objetivos: fechar uma cortina, fechar a porta, apagar a luz; ou com comportamentos subjetivos: inquietação, irritação, estresse - os quais afetam consequentemente sua saúde, por isso a contextualização a partir dos conceitos da psicologia ambiental torna-se importante estruturadora da pesquisa. Entende-se que os estudos pessoa-ambiente constituem um campo propício à compreensão de temas como o bem-estar em ambientes hospitalares (FELIPPE, 2015). Em hospitais públicos esses aspectos tornam-se ainda mais importantes, pois quanto menos tempo o paciente ficar internado, além dos benefícios para sua própria saúde como menos exposição à medicação e menor risco de infecção hospitalar, há também menor desgaste físico e psicológico da equipe médica e de enfermagem.

Assim, para contribuir com o tema, este artigo tem como objetivo, a partir de uma investigação na literatura e em um estudo de caso, identificar quais elementos ambientais são fundamentais para propiciar bem-estar físico e psicológico e contribuem para a humanização no quarto de internação, em estabelecimentos de saúde.

\section{Referencial teórico}

\section{Contribuições da psicologia ambiental}

A psicologia ambiental estuda a relação pessoa-ambiente, ou seja, investiga-se como o ambiente influencia o comportamento humano e como os usuários podem interferir no espaço, devido aos estímulos ambientais percebidos por meio dos elementos arquitetônicos (OKAMOTO, 2002). No caso dos estabelecimentos de saúde, o espaço pode ser um aliado para tornar a estadia do paciente menos penosa, onde é importante 
observar as relações entre o usuário e o ambiente e quais as possíveis formas de configurá-lo para que seja mais adequado ao uso e à apropriação. Portanto, deve-se pensar o espaço para todos os usuários, além de pacientes, e incluir também a equipe médica, de enfermagem, acompanhantes e visitantes, como um facilitador das atividades do dia a dia (CAVALCANTI, 2011).

Estudar os fenômenos do comportamento ambiental - espaço pessoal, privacidade, territorialidade e aglomeração - é importante para caracterizar essa relação pessoa-ambiente. Devido ao espaço físico prover diversos elementos e sua percepção pelos usuários ser captada por múltiplos sentidos ao mesmo tempo, os fenômenos citados auxiliam o entendimento das influências do ambiente sobre as pessoas e vice-versa.

\section{Espaço pessoal}

Definido por Sommer (1973), o espaço pessoal é uma área de limites invisíveis que cerca o corpo de uma pessoa, no qual intrusos não são permitidos. É uma espécie de bolha imaginária ao redor das pessoas, em que estão estipulados seus limites. Gifford (1987) afirma que essa bolha deve ser entendida como um gradiente, com mudança de dimensão e de forma de acordo com as situações, pessoas ou ângulos de orientação - lado a lado ou face a face. Ainda, segundo o autor, a conformação do espaço pessoal depende de três formas de influências: culturais, situacionais e pessoais. Em estabelecimentos de saúde, por exemplo, torna-se importante respeitar o espaço pessoal de cada usuário, dar condições para que cada um adapte o espaço para assegurar maior conforto físico e psicológico, permitir a demarcação do seu espaço individual e colaborar para atenuar situações de constrangimento. Sawada et al. (1998) comenta que o fato de respeitar o espaço pessoal de cada paciente ou estar atento às distâncias interpessoais e privacidade nos procedimentos realizados demonstra um atendimento também mais humano.

\section{Privacidade}

Segundo Altman (1975), a privacidade pode ser definida como o controle pessoal de acesso a si e pode ser considerada como um dispositivo que cada um de nós possui para regular as fronteiras pessoais. De outro modo, a ausência de privacidade causa desconforto e tensão, que pode prejudicar a relação dos usuários em um ambiente. A falta de privacidade é um dos aspectos mais problemáticos em ambientes hospitalares. É um dos principais receios das pessoas referente à internação e uma das causas de estresse ambiental (GAINSBOROUGH; GAINSBOROUGH, 1964). Gifford (1987) afirma que dispor de privacidade é ser capaz de gerenciar o próprio espaço social. O arranjo espacial, responsável pela conformação do espaço físico, deve ser considerado como um elemento primordial na constituição do nível de privacidade desejado. Nos estabelecimentos de saúde, portanto, deve-se considerar a existência de situações bem particulares entre os médicos, enfermeiros e pacientes, que exigem privacidade como conversas pessoais, despir-se para exame, administração de medicamentos, entre outras que podem ser constrangedoras para o paciente. Por isso, a configuração espacial tem um importante papel: o de propiciar o grau de privacidade desejado, permitir ao usuário a opção de controlar o ambiente a sua volta para que se sinta mais confortável e seguro em determinadas situações (VAN DER VOORDT; VAN WEGEN, 2004).

\section{Territorialidade}

A territorialidade é o domínio, posse ou desejo de posse de uma área visível por um indivíduo ou grupo e pode se manifestar com comportamento de apropriação, ocupação, defesa, demarcação, personalização e imposição de limites sociais, como as regras de utilização em ambientes institucionais - horários determinados para utilização de espaços, para tomar banho, para alimentação, entre outros (GIFFORD, 1987). Para Zeisel (2006), por exemplo, a personalização é uma manifestação da identidade, ou seja, é a maneira como o indivíduo se apropria do espaço com suas características pessoais inseridas no ambiente, e assim demarcar seu território.Por meio da apropriação, o espaço pode se transformar em lugar e traz consequências positivas para os usuários, especialmente em ambientes de saúde, pois gera sentimentos de bem-estar e facilita o uso e as relações naquele ambiente, além de colaborar em seu processo de melhora.

\section{Aglomeração}

Aglomeração é a percepção do espaço disponível, ou seja, é a sensação que temos de um determinado momento ou situação em que há pessoas demais no local, mesmo que isso não possa ser comprovado numericamente (TUAN, 1983). A aglomeração é uma experiência multidimensional que pode se referir a nós mesmos ou ao ambiente. Por exemplo, uma pessoa pode se sentir aglomerada em uma sala com uma única pessoa e não se sentir assim em uma festa com inúmeras pessoas a sua volta. A sensação de 
aglomeração causa nos indivíduos alterações fisiológicas e de saúde como, por exemplo, suor, aumento da pressão sanguínea e dos batimentos cardíacos, facilita assim a infecção por doenças de contágio. Além disso, percebem-se comportamentos de agressividade, inquietação, evasão, comportamento não verbal, comportamento espacial e mau humor. Ou seja, se um determinado sujeito sente que há aglomeração em um espaço, ele tomará atitudes conforme sua necessidade, com o objetivo de mudar o espaço ou a situação para que se sinta bem (GIFFORD, 1987).

\section{Atributos ambientais geradores de humanização}

Diversos autores têm suas pesquisas apoiadas em elementos geradores de bem-estar que, por consequência, reduzem o estresse ${ }^{1}$ dos pacientes internados e tornam os espaços mais qualificados, além de contribuir também para a alta hospitalar mais rápida. Pesquisas de Ulrich (1995) apontam a importância dos espaços terem contato com o exterior, proporcionar vistas para a natureza, além de diversos outros elementos que são considerados por ele como redutores do estresse. O autor reconhece que o estresse é o maior obstáculo para a melhora dos pacientes e deve ser tratado com especial atenção, pois envolve a doença em si, os procedimentos médicos, os fatores físicos e sociais do ambiente - como exemplo tem-se os ruídos, a invasão de privacidade e o pouco suporte social que é oferecido.

Ulrich (1995) elenca três componentes para facilitar essa busca por espaços promotores da saúde e bemestar, que são: controle do ambiente, suporte social e distrações positivas. A escolha desses três componentes deve-se, segundo o autor, às evidências científicas de sua influência no bem-estar e nos efeitos fisiológicos relacionados à melhora da saúde.

O controle do ambiente é um importante fator que ajuda a regular o estresse e o bem-estar dos pacientes. As pessoas têm uma forte necessidade de controlar o ambiente e as situações. Assim, para que se sintam mais confortáveis, é importante permitir o controle do espaço a sua volta, como, por exemplo, regular a quantidade de luz sobre os leitos, controlar o acesso a si - privacidade -, o volume do som, a temperatura, entre outros. A ausência desse controle gera estresse e está diretamente relacionada ao aumento da pressão sanguínea, depressão, diminuição da imunidade e passividade (ULRICH, 1995).

O suporte social, por sua vez, corresponde aos benefícios do contato entre pacientes, familiares e amigos. Portanto, os espaços podem incentivar essa interação e apoiar a criação de redes de convívio entre pessoas, bem como propiciar e melhorar os níveis de estresse nos pacientes (ULRICH, 1995). O ambiente pode facilitar essa aproximação por meio de mobiliários flexíveis e confortáveis para promover esse contato, com áreas de visitas nas quais os usuários possam ter a opção de ficarem juntos ou separados, com acessos a jardins ou áreas externas, entre outros recursos. Um ponto importante é que o projeto, sempre que possível, deve promover o contato entre as pessoas, mas não a ponto de invadir a privacidade. Permitir que os pacientes controlem o acesso a si também contribui para seu bem-estar. O ideal seria oferecer aos usuários opção e não os colocar diante de situações indesejadas (ULRICH, 1995).

As distrações positivas são estímulos presentes no ambiente que induzem as pessoas a esquecerem de seus problemas e focarem suas atenções em coisas mais prazerosas, ou seja, em elementos que contribuam para que não se tenham pensamentos negativos e que colaborem para o bem-estar e redução do estresse, tais como a natureza, animais, água, plantas e rostos amigáveis (ULRICH, 1995).

No ponto de vista da arquitetura, os hospitais poderiam buscar individualidade e aconchego, proporcionar liberdade de movimento com a valorização dos espaços de convivência e acolhimento, promover a privacidade e o respeito à dignidade para que o usuário possa reconhecer os valores presentes no seu cotidiano. Antonovsky (1987) criou o termo "salutogênese" para indicar que o projeto do ambiente de saúde deve ter foco no que nos mantém bem, com elementos que deem suporte ao bem-estar. O projeto salutogênico destaca, sobretudo, o impacto dos ambientes sobre as pessoas e que projetos bem desenvolvidos estimulam os usuários, diminuem os riscos em sua própria saúde, fadiga mental e estresse.

Stolkos (1992) traça diretrizes para projetos salutogênicos, a partir das três dimensões da saúde: social, física e mental. A saúde social permite ao indivíduo acesso a uma rede de apoio social, e também a participação no processo de projeto desses ambientes; a saúde física é baseada em um projeto ergonômico que considera as atividades, seja seguro; a saúde mental possibilita controle pessoal de situações. Heerwagen et al. (1995)

${ }^{1}$ Estresse ambiental é causado por ausência ou presença demasiada de estímulos nos ambientes que causam estresse psicológico. Essa situação afeta a saúde dos pacientes e demais usuários dos estabelecimentos de saúde. Moser (1992) define como uma perturbação resultante da interação pessoa-ambiente.

544 Tissot, J. T.; Vergara, L. G. L.; Bins Ely, V. H. M. 
contribuem com essa busca para se obter um projeto salutogênico. Os autores utilizam os termos: coesão social, para indicar que o ambiente deve prover pontos de encontro formais ou informais; recuperação e relaxamento, com quartos silenciosos, iluminação suave, acesso à natureza e uma boa vista para o exterior; controle pessoal para permitir ao indivíduo controle de iluminação, luz, som, temperatura e ter direito a quartos privativos, que gerencie o acesso de quem entra. Abaixo apresenta-se uma tabela síntese referente ao pensamento dos autores citados e os componentes por eles considerados importantes para a obtenção de projetos voltados à promoção da saúde e do bem-estar dos usuários. São considerados também os eixos estabelecidos pela Cartilha da Ambiência (BRASIL..., 2010), pois incluem estratégias para a busca de ambientes mais humanizados.

Constata-se, a partir da tabela síntese acima, que há um consenso entre os autores, de que, mesmo com terminologias diferentes, para o projeto promover bem-estar aos usuários devem colaborar para a redução do estresse e ajudar na recuperação dos pacientes. Ao compilar os dados acima, devem-se considerar alguns critérios que incluem:

(a) prever espaços que deem suporte para o paciente, no sentido de permitir encontros e estimular as relações sociais;

(b) fornecer estímulos moderados para que o paciente foque sua atenção em outros elementos que não seja na sua dor; e

(c) controlar o ambiente e as situações nas quais o paciente possa escolher interagir ou não com outras pessoas e controlar alguns elementos do ambiente a sua volta como luzes, cortinas, equipamentos, mobiliário e outros.

Para o desenvolvimento deste artigo, conforme apresenta-se no Quadro 1, tomam-se por base os conceitos estabelecidos por Ulrich (1995) os quais comprovam que o suporte social, as distrações positivas e o controle do ambiente reduzem o estresse e promovem bem-estar à saúde dos usuários. Porém, acrescenta-se mais um componente visto como fundamental para complementar esse tripé, baseado nos estudos de Stokols (1992) e no Ministério da Saúde (BRASIL, 2010), segundo o qual o ambiente também deve prover suporte às atividades (saúde física e espaço facilitador, respectivamente). Assim, ao planejar espaços de saúde, ambientes e principalmente os quartos - que são espaços nos quais os pacientes permanecem por mais tempo e nos quais são realizadas atividades e procedimentos importantes pela equipe médica e de enfermagem devem primar pelo conforto e pela segurança de todos os usuários envolvidos. Os projetos dos quartos podem colaborar para que toda e qualquer atividade seja realizada sem nenhum tipo de obstáculo e que o ambiente seja visto como um facilitador desse processo.

Quadro 1 - Componentes para humanização dos ambientes segundo Stokols (1992), Ulrich (1995), Heerwagen et al. (1995) e Ministério da Saúde (BRASIL, 2010)

\begin{tabular}{|l|l|l|l|l|}
\hline AUTORES & \multicolumn{1}{|c|}{ INTERAÇÃO } & \multicolumn{1}{c|}{ DISTRAÇÃO } & \multicolumn{1}{c|}{ CONTROLE } & \multicolumn{1}{c|}{ TAREFAS } \\
\hline $\begin{array}{l}\text { Stokols } \\
(1992)\end{array}$ & $\begin{array}{l}\text { Saúde social: } \\
\text { acesso a rede de } \\
\text { apoio social. }\end{array}$ & - & $\begin{array}{l}\text { Saúde mental: } \\
\text { controle pessoal e } \\
\text { de situações. }\end{array}$ & $\begin{array}{l}\text { Saúde física: } \\
\text { projeto } \\
\text { ergonômico. }\end{array}$ \\
\hline Ulrich (1995) & $\begin{array}{l}\text { Suporte social: } \\
\text { ambientes que } \\
\text { promovam rede de } \\
\text { apoio às pessoas. }\end{array}$ & $\begin{array}{l}\text { Distração positiva: } \\
\text { elementos que } \\
\text { distraiam o paciente e } \\
\text { tirem o foco da } \\
\text { doença. }\end{array}$ & $\begin{array}{l}\text { Controle do } \\
\text { ambiente: controlar } \\
\text { o espaço a sua volta } \\
\text { e o acesso a si. }\end{array}$ & - \\
\hline $\begin{array}{l}\text { Heerwagen } \text { et } \\
\text { al. (1995) }\end{array}$ & $\begin{array}{l}\text { Coesão social: } \\
\text { pontos de encontro } \\
\text { formal ou informal. }\end{array}$ & $\begin{array}{l}\text { Recuperação e } \\
\text { relaxamento: quartos } \\
\text { silenciosos, boa } \\
\text { iluminação, vistas } \\
\text { para natureza. }\end{array}$ & $\begin{array}{l}\text { Controle pessoal: } \\
\text { controle de } \\
\text { iluminação, som, } \\
\text { temperatura e } \\
\text { acesso aos quartos. }\end{array}$ & - \\
\hline $\begin{array}{l}\text { Ministério da } \\
\text { Saúde } \\
\text { (BRASIL, } \\
\text { 2010) }\end{array}$ & $\begin{array}{l}\text { Encontro de } \\
\text { sujeitos: espaços } \\
\text { que possibilitem a } \\
\text { vivência entre } \\
\text { usuários. }\end{array}$ & $\begin{array}{l}\text { Confortabilidade: } \\
\text { espaços que } \\
\text { valorizem elementos } \\
\text { que interagem com as } \\
\text { pessoas. }\end{array}$ & $\begin{array}{l}\text { Espaço } \\
\text { facilitador: espaço } \\
\text { como facilitador } \\
\text { do processo de } \\
\text { trabalho. }\end{array}$ \\
\hline
\end{tabular}




\section{Método}

Para realização do estudo de caso foi escolhido um hospital municipal ${ }^{2}$ de médio porte, térreo, do tipo pavilhonar, com foco na ala de clínica médica - quartos de internação - local onde os pacientes ficam internados, de ambos os gêneros e diferentes faixas etárias, com problemas exclusivamente clínicos. O tempo de permanência é variado, onde ficam por dias, semanas ou até meses. Pretende-se, portanto, avaliar o quarto de internação sob a ótica do pesquisador e dos usuários ${ }^{3}$ a fim de verificar de que forma esse espaço poderia ser mais qualitativo. Foram selecionados diferentes métodos de pesquisa para que os resultados esperados, inicialmente propostos na pesquisa, fossem alcançados e estão expostos no Quadro 2. Na primeira coluna são apresentados os métodos utilizados, sendo eles: Visita exploratória (ORNSTEIN, 1992). Entrevistas semiestruturadas (LAKATOS; MARCONI, 2000), Seleção visual (SANOFF, 1991), Observação do comportamento (SOMMER; SOMMER, 1997) e Análise dos traços físicos (ZEISEL, 2006). Na segunda coluna tem-se o objetivo da utilização do método, seguido do local onde foi realizado e na última coluna, com qual usuário o método foi aplicado.

Quadro 2 - Métodos utilizados na pesquisa

\begin{tabular}{|c|c|c|c|}
\hline Métodos & Objetivo & Onde foi realizado & Com quem \\
\hline $\begin{array}{l}\text { Visita } \\
\text { exploratória } \\
\text { (ORNSTEIN, } \\
\text { 1992). }\end{array}$ & $\begin{array}{l}\text { Verificação de aspectos positivos e } \\
\text { negativos do espaço, realizada de } \\
\text { modo sistemático, através da } \\
\text { utilização de planilhas. }\end{array}$ & $\begin{array}{l}\text { Entorno do hospital, áreas } \\
\text { externas, ala de clínica } \\
\text { médica e quartos de } \\
\text { internação. }\end{array}$ & $\begin{array}{l}\text { Percepção e } \\
\text { análise do } \\
\text { pesquisador. }\end{array}$ \\
\hline $\begin{array}{l}\text { Entrevistas } \\
\text { semiestruturadas } \\
\text { (LAKATOS; } \\
\text { MARCONI, } \\
\text { 2003). }\end{array}$ & $\begin{array}{l}\text { Contato direto com o usuário para } \\
\text { identificar suas emoções e reações } \\
\text { durante as respostas. Os dados obtidos } \\
\text { foram inicialmente tratados por meio } \\
\text { de análise de conteúdo, o que } \\
\text { possibilitou, posteriormente, uma } \\
\text { análise da frequência dos resultados } \\
\text { mediante software MAXQDA. }\end{array}$ & $\begin{array}{l}\text { Foram realizadas } \\
\text { entrevistas-piloto com } \\
\text { objetivo de averiguar se as } \\
\text { perguntas selecionadas } \\
\text { eram pertinentes e sobre a } \\
\text { necessidade de abordar } \\
\text { outras questões relevantes, } \\
\text { comentadas pelos } \\
\text { entrevistados. }\end{array}$ & $\begin{array}{l}\text { Três pacientes } \\
\text { e três técnicos } \\
\text { de } \\
\text { enfermagem. }\end{array}$ \\
\hline $\begin{array}{l}\text { Seleção visual } \\
\text { (SANOFF, } \\
\text { 1991). }\end{array}$ & $\begin{array}{l}\text { Compreensão do imaginário dos } \\
\text { usuários, além de identificar os } \\
\text { valores que atribuem ao ambiente } \\
\text { estudado (RHEINGANTZ et al., } \\
\text { 2009). }\end{array}$ & $\begin{array}{l}\text { Quartos de internação e nos } \\
\text { postos de enfermagem } \\
\text { (local onde os profissionais } \\
\text { ficavam). }\end{array}$ & $\begin{array}{l}\text { Funcionários e } \\
\text { pacientes. }\end{array}$ \\
\hline $\begin{array}{l}\text { Observação do } \\
\text { comportamento } \\
\text { (SOMMER; } \\
\text { SOMMER, } \\
\text { 1997). }\end{array}$ & $\begin{array}{l}\text { Analisar o comportamento dos } \\
\text { usuários e suas atividades e fornecer } \\
\text { dados sobre o comportamento real em } \\
\text { um ambiente natural. O registro é feito } \\
\text { mediante anotação, em ficha } \\
\text { específica. }\end{array}$ & $\begin{array}{l}\text { Quartos dos pacientes } \\
\text { entrevistados. No caso dos } \\
\text { banheiros, destaca-se que } \\
\text { devido à impossibilidade } \\
\text { de observação será } \\
\text { considerada a análise do } \\
\text { ambiente sem ocupação. }\end{array}$ & $\begin{array}{l}\text { Pacientes e } \\
\text { acompanhantes. }\end{array}$ \\
\hline $\begin{array}{l}\text { Análise dos } \\
\text { traços físicos } \\
\text { (ZEISEL, 2006). }\end{array}$ & $\begin{array}{l}\text { Procurar no ambiente físico vestígios } \\
\text { de atividades anteriores deixadas pelos } \\
\text { usuários de forma consciente. }\end{array}$ & $\begin{array}{l}\text { Quartos de internação e } \\
\text { banheiros. }\end{array}$ & $\begin{array}{l}\text { Percepção e } \\
\text { análise do } \\
\text { pesquisador. }\end{array}$ \\
\hline
\end{tabular}

\footnotetext{
${ }^{2}$ Os pesquisadores obtiveram autorização da direção do hospital para a realização da pesquisa.

${ }^{3}$ A pesquisa seguiu a Resolução $n^{\circ} 466$, de 12 de dezembro de 2012, com projeto registrado na Plataforma Brasil e aprovado pelo Comitê de Ética em Pesquisas com seres humanos em 05/02/2015, número do parecer 946.995/ CAAE: 39274314.3.0000.535. 0 acesso às informações é restrito ao pesquisador. Os procedimentos adotados que envolvem os usuários não ofereceram risco algum aos participantes, nem sequer desconforto ou estresse. Ainda assim, os participantes foram livres para interromper sua participação a qualquer momento. Também não houve despesas para os participantes e todos os gastos com a pesquisa foram de responsabilidade do pesquisador.
} 


\section{Resultados e discussões}

Posterior à aplicação da metodologia e análise de todos os dados pode-se verificar que os resultados mais relevantes foram obtidos a partir da inquirição - entrevistas. Elaborou-se, portanto, a Tabela 1 que sintetiza os resultados e responde à pergunta da pesquisa: "quais elementos ambientais do quarto de internação são mais significativos para os usuários e contribuem para a humanização?" e favorece assim a permanência dos usuários, principalmente dos pacientes. Na primeira coluna do quadro abaixo têm-se os principais usuários, seguidos pelos componentes da humanização determinados na pesquisa. Na terceira coluna os elementos considerados por cada grupo de usuários como prioritário e na última coluna sua porcentagem. Os resultados obtidos são ainda discutidos com a literatura e avaliados conforme gênero e idade dos pacientes.

$\mathrm{Na}$ Tabela 1, pode-se constatar que relacionado ao suporte social, suporte às atividades e controle do ambiente, os elementos considerados importantes são os mesmos, visto que no caso dos pacientes também citaram o condicionador de ar para controle do ambiente. Houve discordância apenas no componente distrações positivas, ao qual os funcionários elencaram o jardim como primordial, e em contrapartida os pacientes preferiram as janelas.

Para prover suporte social a ambos os usuários, o elemento "espaço específico para outras atividades" foi considerado como mais significativo. A existência de espaços destinados à realização de outras atividades influencia diretamente na rotina dos pacientes e funcionários. Dispor de ambientes com essas funções no hospital permite que os indivíduos possam escolher entre estar só ou em contrato com outras pessoas. Para os pacientes, esses espaços poderiam ser destinados à socialização, já que permanecem a maior parte do tempo em seus quartos, como, por exemplo, para a realização de trabalhos manuais, leituras, assistir televisão ou apenas para conversar. Ao se comparar as respostas obtidas nesta pesquisa, entre gênero e idade, percebe-se maior incidência na indicação desse elemento pelo grupo jovem, sem diferença considerável entre gêneros. Por ser uma população mais ativa, o fato de estarem internados, sem possibilidade de sair, gera estresse e ansiedade. O grupo de idosos também idealiza tais espaços pela necessidade de convívio social com outras pessoas, pois muitos não possuem acompanhantes e estão sujeitos a depressão. Foram constatados, ainda, durante as observações, comportamentos relacionados à inquietação, ansiedade e estresse, pelo fato de os pacientes ficarem o dia todo em seus quartos, sem distração e sem realizar atividades que os ajudem a passar o tempo. A elaboração de espaços diferenciados para permanência dos usuários pode ser uma forma de amenizar os sentimentos negativos em decorrência da sensação de institucionalização.

Tabela 1 - Elementos mais citados em porcentagens pelos usuários

\begin{tabular}{l|l|c}
\hline \multicolumn{1}{c|}{ Componente da humanização } & \multicolumn{1}{|c}{ Elemento mais citado } & $\begin{array}{c}\text { Porcentagem } \\
\text { FUNCIONÂRIOS }\end{array}$ \\
\hline Suporte social & Espaço específico para outras atividades & $71,43 \%$ \\
\hline Suporte às atividades & $\begin{array}{l}\text { Leiaute flexível (dimensionamento do } \\
\text { espaço com arranjo do mobiliário) }\end{array}$ & $71,43 \%$ \\
\hline Controle do ambiente & $\begin{array}{l}\text { Leiaute flexível (dimensionamento do } \\
\text { espaço com arranjo do mobiliário) }\end{array}$ & $100 \%$ \\
\hline Distrações positivas & Jardins & $71,43 \%$ \\
\hline Componente da humanização & \multicolumn{1}{c}{ Elemento mais citado } & $\begin{array}{c}\text { Porcentagem } \\
\text { PACIENTES }\end{array}$ \\
\hline Suporte social & Espaço específico para outras atividades & $83,33 \%$ \\
\hline Suporte às atividades & $\begin{array}{l}\text { Leiaute flexível (dimensionamento do } \\
\text { espaço com arranjo do mobiliário) }\end{array}$ & $20 \%$ \\
\hline Controledo ambiente & $\begin{array}{l}\text { Leiaute flexível (dimensionamento do } \\
\text { espaço com arranjo do mobiliário) e } \\
\text { condicionador de ar }\end{array}$ & $63,33 \%$ \\
\hline Distrações positivas & Janelas & $60 \%$ \\
\hline
\end{tabular}


Para o componente "suporte às atividades" o elemento "leiaute flexível (dimensionamento do espaço com arranjo do mobiliário)" se destaca como significativo na preferência dos usuários. Para os pacientes, principalmente idosos, o leiaute interfere diretamente na realização das atividades do dia a dia, onde foram mencionadas dificuldades na utilização do banheiro por não possuir acessibilidade e, como consequência, causa insegurança. Durante a análise dos traços físicos foi constatado o uso de cadeira plástica em alguns banheiros para servir de apoio ao paciente. O uso de cadeiras próprias para banho seria possível, caso as dimensões do ambiente estivessem de acordo com a NBR 9050 (ABNT, 2004), para permitir o giro e deslocamento da cadeira pelo usuário. Os funcionários relataram que o leiaute poderia, ainda, contribuir para que as atividades de rotina fossem realizadas de forma mais ágil e segura, com mobiliários e equipamentos flexíveis. No caso específico desta pesquisa, em que os quartos são coletivos, o leiaute poderia contribuir, também, para garantir mais privacidade e conforto nas atividades realizadas no leito.

Para o componente "controle do ambiente", o elemento "leiaute flexível (dimensionamento do espaço com arranjo do mobiliário)" obteve a maior frequência nas respostas de ambos os usuários, porém cabe ressaltar que no caso dos pacientes o "condicionador de ar" obteve a mesma quantidade de menções do leiaute, onde foi considerado por esse grupo específico como importante para controlar o conforto ambiental. A preferência pelo "leiaute flexível" está diretamente relacionada às condições de privacidade, por serem quartos coletivos. Para essa tipologia de quarto, o emprego de elementos que facilitem a formação de territórios e aumente a privacidade entre os indivíduos, de forma a separar o espaço de cada um, teria um efeito positivo. Durante as observações realizadas, também foi observada a ausência de privacidade visual e sonora devido às portas dos quartos estarem sempre abertas, o que faz com que os usuários se sintam vigiados o tempo todo. Se o leiaute permitisse a configuração de arranjos espaciais de modo a favorecer a criação de territórios, consequentemente proporcionaria o controle da privacidade para os pacientes e demais usuários. A presença de elementos ambientais com características flexíveis, como o mobiliário, por exemplo, permitiria que algumas condições ambientais fossem controladas, pelo menos no que diz respeito às distâncias e ao seu posicionamento, de acordo com as preferências de cada um.

Para "distrações positivas", os funcionários elencaram o "jardim" como prioritário. O contato com a natureza interfere positivamente no bem-estar dos usuários, principalmente nos pacientes que estão sensíveis aos estímulos do ambiente. Assim, os níveis de ansiedade e estresse podem diminuir e gerar maior satisfação. Os jardins, além de restaurar a saúde, também contribuem para o conforto térmico, ao minimizar os ganhos de calor nos ambientes internos. Pode-se ainda pensar na utilização de água em espaços ajardinados, pois influencia na sensação psicológica, além de contribuir, no caso dos funcionários, para reduzir a tensão, descontrair e relaxar devido ao exercício de atividades que exigem muita concentração. Os pacientes consideram a "janela" como elemento prioritário, com a maior frequência nas respostas. A necessidade de olhar para fora minimiza os efeitos da institucionalização e permite o contato com o exterior. É indicado ainda que haja a possibilidade de controle do seu sistema de fechamento, para que se regule a quantidade de estímulos recebidos como, por exemplo, uma janela que possui persiana ou cortina que permita ajustar a intensidade da luz natural no ambiente. A importância da janela se dá devido à possibilidade de garantir conforto visual, térmico e psicológico para os pacientes e proporcionar a percepção da variação da luz do dia, o contato com a vegetação, o relaxamento, e contribuir para a melhora da permanência dos pacientes.

O paciente internado se desliga do mundo exterior e, de acordo com a condição em que se encontra, a janela é o único meio de comunicação. Sua localização no ambiente, dimensão, mecanismo de funcionamento/abertura e a vista que proporciona pode ser um dos meios de contato mais importantes entre o paciente e o ambiente externo. Assim, o hospital em estudo poderia ter uma relação interior/exterior mais bem aproveitada com grandes aberturas que pudessem permitir esse contato. Por possuir películas foscas nas janelas, a visão é inibida, e o paciente fica sem nenhum tipo de distração. A estimulação proveniente do ambiente externo é importante para evitar o estresse e a monotonia. Ficou ainda mais evidente essa necessidade, uma vez que durante a análise dos traços físicos as janelas se apresentaram com as películas danificadas em uma tentativa de o paciente ter contato com o exterior.

\section{Considerações finais}

Até pouco tempo atrás se acreditava que para o ambiente ser humanizado era necessário dispor de decoração, cores diferenciadas, quadros, fontes, entre outros elementos, que trouxessem aos usuários a sensação de estar em um hotel e não dentro de um hospital. Mediante essa observação, acreditava-se que apenas hospitais privados poderiam contemplar espaços humanizados, visto que seria necessário grande investimento financeiro para dispor desses elementos nos ambientes. No entanto, esta pesquisa efetuada em 
um hospital público demonstrou que é possível humanizar os espaços por meio de outros elementos, inerentes à própria arquitetura, os quais foram elencados pelos usuários. Tais elementos - como a janela, o jardim, espaços destinados a outras atividades ou o próprio leiaute do ambiente - poderiam ser repensados e inseridos no projeto arquitetônico de forma a atender as demandas dos diferentes usuários.

O elemento janela, por exemplo, citado como essencial para os pacientes como forma de obter distrações positivas, poderia ter seu peitoril mais baixo de forma a possibilitar, aos pacientes acamados, visualizar o exterior. Assim, pensar o elemento de modo diferenciado, sem seguir um padrão de dimensão e forma, poderia ser uma estratégia para obter ambientes mais acolhedores e humanizados. Ao considerar que as vistas externas minimizam a sensação de institucionalização, o diálogo com o que ocorre do lado de fora seria necessário e fundamental para o bem-estar dos usuários.

Houve por parte dos funcionários uma grande frequência em mencionar o jardim como elemento para distração que, interno ou externo, corrobora com outras pesquisas ao apresentá-lo como restaurador da saúde. Fica evidente nesta pesquisa que além dos pacientes os demais usuários dos estabelecimentos de saúde possuem grande necessidade de alívio psicológico devido as suas rotinas estressantes, proporcionado pela presença da vegetação.

O dimensionamento do espaço e a disposição do mobiliário muitas vezes são considerados suficientes apenas por seguirem as determinações de normas e de regulamentações. Porém, o leiaute do ambiente se apresenta como fundamental para a realização das atividades de forma eficiente pelos usuários, visto ainda que nesta pesquisa sua função também foi associada ao controle da privacidade. Ao projetar ambientes de longa permanência, principalmente quartos de internação, pode-se oportunizar a criação de territórios e permitir que o usuário tenha controle do espaço. Decidir quando e com quem se quer interagir contribui para uma permanência mais satisfatória.

A flexibilidade do leiaute e dos mobiliários também pode permitir que os espaços tenham diferentes usos, seja no cumprimento de sua função primária - atendimento e procedimentos com os pacientes e seu repouso - ou na promoção da socialização entre os usuários, condição esta vista como essencial. Devido ao fato de que os funcionários possuem uma rotina exaustiva e que os pacientes possuem sentimentos de isolamento e institucionalização, espaços que permitam aos usuários realizarem outras atividades são positivos, pois colaboram para o bem-estar.

Elementos como o condicionador de ar, para regular a temperatura de forma mecânica, e os jardins, que possibilita a criação de microclimas de forma natural, contribuem positivamente, a fim de garantir aos usuários melhor conforto ambiental. Cabe ressaltar que os equipamentos instalados devem ser passíveis de controle pelos usuários. A vegetação, além de contribuir para adequar a temperatura, também possibilita que as vistas externas sejam agradáveis, visto seu potencial restaurador já acima comentado. Tais elementos devem ser pensados nas etapas que antecedem o projeto, para evitar custos adicionais e garantir uma composição arquitetônica mais harmoniosa. Planejar os ambientes de acordo com os anseios dos usuários é um primeiro passo para assegurar uma melhor permanência, já que elementos associados ao bem-estar garantem a humanização.

Durante a revisão de literatura, quando os componentes da humanização e seus elementos foram determinados, percebeu-se que alguns elementos mesmo com funções diferentes se repetiam em mais de um componente. Acreditou-se assim que esses elementos recorrentes poderiam ser considerados mais humanizadores se comparados àqueles que se destacam apenas em um componente. Por meio do contato com os usuários, a partir da inquirição, pode-se concluir que independentemente da quantidade de vezes que um elemento se apresenta, a prioridade dos usuários está relacionada à função do elemento e nos benefícios positivos proporcionados, como no caso dos jardins, janelas e condicionador de ar, que apesar de se destacarem apenas em um componente foram considerados fundamentais para a humanização. Já os elementos leiaute flexível e espaços específicos para outras atividades - também considerados prioritários pelos usuários - se repetem em mais de um componente, pois possuem funções diversificadas. Percebe-se que em relação aos atributos do ambiente, os elementos arquitetônicos que poderiam contribuir para uma permanência mais satisfatória dos usuários são pouco explorados.

As janelas seguem um padrão que não permite a visualização para o exterior, tampouco o controle de iluminação natural. A presença de vegetação ocorre apenas nas áreas de acesso. Entre os blocos de internação há apenas grama, porém os usuários não conseguem visualizá-la. O leiaute não permite arranjos diferenciados e o mobiliário, apesar de não ser fixo, é pesado, o que dificulta alterações em seu posicionamento. Ainda que o quarto esteja com as dimensões nos padrões determinados pela RDC 50 
(AGÊNCIA..., 2002), o banheiro não atende as condições mínimas de acessibilidade para pacientes e para que os funcionários possam auxiliá-los no banho.

O espaço deve ser um facilitador das relações interpessoais, estimular a criação de redes de convívio para os pacientes, a equipe médica, os visitantes, como também para os demais profissionais de saúde, além de facilitar o contato com elementos que reduzam o estresse. $O$ ambiente físico é peça fundamental na recuperação da saúde e na qualidade da permanência dos usuários.

A falta de conhecimento sobre os benefícios da humanização muitas vezes acaba por tornar os ambientes precários e afeta a saúde dos usuários. Humanizar os ambientes significa torná-los adequados às condições humanas, torná-los apropriados e apropriáveis (BINS ELY, 2013). Para humanizar, além de pensarmos nos usuários e nas atividades, o ambiente físico deve ser considerado como parte do processo e contribuir para o bem-estar e melhor qualidade de vida de todos. Buscar elementos que humanizam os espaços, focados no bem-estar dos usuários, pode colaborar na otimização e qualificação dos ambientes de saúde, ambientes esses que requerem atenção devido à condição na qual seus usuários muitas vezes se encontram.

\section{Referências}

AGÊNCIA NACIONAL DE VIGILÂNCIA SANITÁRIA. RDC n. 50 - regulamento técnico para planejamento, programação, elaboração e avaliação de projetos físicos de estabelecimentos assistenciais de saúde. Brasília, 2002.

ALTMAN, I. The environmentand social behavior. California: Brooks Cole, 1975.

ANTONOVSKY, A. UnravelingtheMysteryof Health: howpeoplemanage stress andstaywell. San Francisco: Jossey-Bass, 1987.

ASSOCIAÇÃO BRASILEIRA DE NORMAS TÉCNICAS. NBR 9050: acessibilidade a edificações, mobiliário, espaços e equipamentos urbanos. Rio de Janeiro, 2004.

BINS ELY, V. H. M. Notas de disciplina: avaliação em função do Usuário. 2013. Programa de PósGraduação em Arquitetura e urbanismo, Universidade Federal de Santa Catarina. Florianópolis, 2013. Notas da disciplina.

BRASIL. Ministério da Saúde. Secretaria de Atenção à Saúde. Política Nacional de Humanização da Atenção e Gestão do SUS. O Humaniza SUS na atenção básica / Ministério da Saúde, Secretaria de Atenção à Saúde, Política Nacional de Humanização da Atenção e Gestão do SUS. 1. ed. 1. reimpr. Brasília: Ministério da Saúde, 2010.

CAVALNCANTI, P. B. A humanização de unidades clínicas de hospital-dia: vivência e apropriação pelos usuários. Rio de Janeiro, 2011. Tese (Doutorado em Arquitetura e Urbanismo) - Programa de PósGraduação em Arquitetura e Urbanismo, Universidade Federal do Rio de Janeiro, Rio de Janeiro, 2011.

DILANI, A. Psychosociallysupportive design, Scandinavianhealthcare design. In: DILANI, A. (org.). Design \&health: the therapeutic benefits of design. Estocolmo: Svensk Byggtjanst, 2001.

ERICKSSON, J. Medical research and its impacto $n$ health care design. In: DILANI, A. (org.). Design \&health: the therapeutic benefits of design. Estocolmo: Svensk Byggtjanst, 2001.

FELIPPE, M. L. Ambiente físico e linguagem ambiental no processo de restauração afetiva do estresse em quartos de internação pediátricos. Ferrara, 2015. Tese(Doutorado em Tecnologia da Arquitetura) Departamento de Arquitetura, Universidade de Ferrara, Ferrara, 2015.

GAINSBOROUGH, H.; GAINSBOROUGH, J. Principlesof hospital design. Londres: Architectural Press, 1964.

GIFFORD, R. Environmental psychology: principlesandpractice. Califórnia: Allyn \& Bacon,1987.

HEERWAGEN, J. H. et al. Environmental design, work, and wellbeing: managing occupational stress through changes in work place environment. Official Journal of the American Association of Occupational Health Nurses, v. 43, n. 9, p. 458-468, set. 1995.

LAKATOS, E. M.; MARCONI, M. A. Fundamentos de metodologia científica. 5. ed. São Paulo: Atlas, 2003.

MOSER, A. Ética e filosofia no abate de animais para consumo. Anais de Etologia, v. 10, p. 123-132, 1992. 
OKAMOTO, J. Percepção ambiental e comportamento: visão holística da percepção ambiental na arquitetura e na comunicação. São Paulo: Mackenzie, 2002.

ORNStEIn, S. W. AvaliaçãoPós- Ocupação (APO) do AmbienteConstruído. São Paulo: Studio Nobel: Editora da USP, 1992.

RHEINGANTZ, P. A. et al. Observando a qualidade do lugar: procedimentos para a avaliação pósocupação. Rio de Janeiro: PROARQ/FAU-UFRJ, 2009.

SANOFF, H. Visual research methods in design. New York: Van Nostrand Reinhold, 1991.

SAWADA, N. O. et al. Invasão do território e espaço pessoal dopaciente hospitalizado: adaptação de instrumento de medida para a cultura brasileira. Revista Latino-Americana de Enfermagem,Ribeirão Preto, v. 6, n. 1, p. 5-10, jan. 1998.

SOMMER, B.; SOMMER, R. Tools and techniques. New York: Oxford University Press, 1997.

SOMMER, R. Espaço pessoal. São Paulo: Editora da Universidade de São Paulo, 1973.

STOKOLS, D. Establishing and maintaining healthy environments. American Psychologist, v. 47, n. 1, p. 6-22, 1992.

TUAN, Y.-F. Espaço e lugar: a perspectiva da experiência. São Paulo: Difel, 1983.

ULRICH, R. S. Effects of healthcare interior design on wellness: theory and recent scientific research. In: SYMPOSIUM ON HEALTHCARE DESIGN, 4., Bston, 1991. Proceedings [...] New York, 1995.

VAN DER VOORDT, T. J. M.; VAN WEGEN, H. B. R. Arquitetura sob o olhar do usuário. São Paulo: Oficina de Textos, 2004.

VERDERBER, S.; FINE, D. J. Healthcare architecture in a era of radical transformation. New Haven,Londres: Yale University Press, 2000.

ZEISEL, J. Inquiry by design: tools for environment-behavior research. New York: Cambridge University Press, 2006.

\title{
Agradecimentos
}

Ao PósARQ/UFSC e à Coordenação de Aperfeiçoamento de Pessoal de Nível Superior (Capes), por possibilitar a realização desta pesquisa através da concessão da bolsa, à direção do Hospital pela autorização e a todos os participantes que contribuíram de maneira direta ou indireta.

Juliana Tasca Tissot

Departamento de Pós-Graduação em Arquitetura e Urbanismo | Universidade Federal de Santa Catarina | Rua Delfino Conti, s/n, Campus Universitário Reitor João David Ferreira Lima | Florianópolis - SC - Brasil | CEP 88040-900 | Tel.: (48) 3721-9797 | E-mail: jutissot@hotmail.com

\section{Lizandra GraciaLupi Vergara}

Departamento de Pós-Graduação em Arquitetura e Urbanismo | Universidade Federal de Santa Catarina | E-mail: I.vergara@ufsc.br

Vera Helena Moro Bins Ely

Departamento de Pós-Graduação em Arquitetura e Urbanismo | Universidade Federal de Santa Catarina | E-mail: jutissot@hotmail.com

\author{
Ambiente Construído \\ Revista da Associação Nacional de Tecnologia do Ambiente Construído \\ Av. Osvaldo Aranha, $99-3^{\circ}$ andar, Centro \\ Porto Alegre - RS - Brasil \\ CEP $90035-190$ \\ Telefone: +55 (51) 3308-4084 \\ Fax: +55 (51) 3308-4054 \\ www.seer.ufrgs.br/ambienteconstruido \\ E-mail: ambienteconstruido@ufrgs.br
}

